Check for updates

Cite this: RSC Adv., 2017, 7, 37720

Received 9th May 2017

Accepted 10th July 2017

DOI: 10.1039/c7ra05217k

rsc.li/rsc-advances

\section{Phase tuned synthesis of titanium dioxide nanoparticles for room temperature enhanced ammonia detection}

\author{
Sameeha Mohamed Sali, ${ }^{a}$ Soumya Joy, $\dagger^{a}$ N. Meenakshisundaram, ${ }^{b}$ \\ Rakesh Kumar Karn, ${ }^{C}$ C. Gopalakrishnan, ${ }^{d}$ P. Karthick, (D) ${ }^{\text {ce }}$ K. Jeyadheepan (iD) ce \\ and Kamatchi Sankaranarayanan (D) *a
}

Synthesis of titanium dioxide nanoparticles is gaining more importance in the field of nanotechnology due to their application in the gas/vapor sensing field. The present study deals with the synthesis of titanium dioxide nanoparticles from titanium isopropoxide solution using various ionic liquids as phase tuning agents. XRD results revealed the crystalline nature and presence of anatase and rutile phases of synthesized titanium dioxide nanoparticles. The shape and size of the particles were analyzed using TEM and SEM images, which indicated their morphology. The adhesion of dip-coated thin films was obtained from contact angle measurements and correlated with surface roughness. The gas sensing ability of the synthesized titanium dioxide nanoparticles was tested by checking the level of chemisorption and measuring the change in resistance of the samples in the presence and absence of gas inside an airtight chamber and plotting it as a function of time. The sensing studies performed on the samples showed that the $\mathrm{TiO}_{2}$ samples with ionic liquid 1-ethyl-3-methylimidazolium hexafluorophosphate [EMIM-PF $]$, with the highest anatase phase percentage, displayed the best ammonia sensing. The results suggest that the sol-gel prepared $\mathrm{TiO}_{2}$ acts as an excellent gas sensor and on adding ionic liquid, the performance is further enhanced.

\section{Introduction}

Detection of gases suspended in air, particularly those that are toxic or flammable, has become highly important as the rate of pollution is increasing day by day. Even though ammonia is a naturally produced substance and found in low ppb levels in air, its inhalation causes damage to the respiratory tract, depending on the concentration, $\mathrm{pH}$, extent of inhalation and continuance of exposure. ${ }^{1-3}$ The Agency for Toxic Substances and Disease Registry (ATSDR) of the U.S. Department of Health and Human Services in its peer-reviewed profile identifies that the exposure to very high concentrations of ammonia $(>1500$ $\mathrm{ppm}$ ) even for short durations ( $<0.5$ hours per day) may cause extensive edema, purulent bronchitis, and highly distended

\footnotetext{
${ }^{a}$ Department of Energy and Environment, NIT, Tiruchirapalli 620015, India. E-mail: kamatchi.sankaran@gmail.com

${ }^{b}$ Department of Physics, Vivekananda College, Tiruvedakam West, Madurai 625234, India

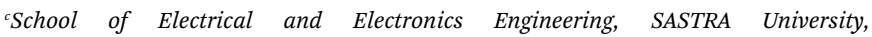
Tirumalaisamudram, Thanjavur 613 401, India

${ }^{d}$ Nanotechnology Research Centre, SRM University, Kattangulatur, Kancheepuram-603 203, India

${ }^{e}$ Multifunctional Materials \& Devices Lab, Anusandhan Kendra-II, SASTRA University, Tirumalaisamudram, Thanjavur 613 401, India

$\dagger$ Authors contributed equally for this work.
}

lungs, leading to elevated pulse and blood pressure, cardiac arrest, permanent blindness and even death. ${ }^{4}$ This requires the development of highly sensitive, selective and acceptable fast detection of ammonia with lower operating power. An economic sensor that can sense ammonia irrespective of operating temperature could solve the issue by monitoring and measuring the amount of ammonia in the environment. Considerable research has been carried out to detect the presence of ammonia, of which thin-film chemo-resistive gas sensors have proved to show excellent results. Various thin-film gas sensors such as $\mathrm{V}_{2} \mathrm{O}_{5}$, $\mathrm{ZnO}$, SnO, and $\mathrm{TiO}_{2}$ (ref. 5-8) have been used as gas sensor elements; however, among them, $\mathrm{TiO}_{2}$ has proved to detect gas with the highest efficiency in ammonia sensing. ${ }^{8}$

Titanium dioxide nanoparticles $\left(\mathrm{TiO}_{2} \mathrm{NPs}\right)$ have gained popularity due to their properties such as wide band gap, stability, photocatalytic behavior, ${ }^{9}$ porosity, large specific surface area and, most importantly, low cost of production and easy availability. $\mathrm{TiO}_{2}$ exists in three different crystalline phases, namely anatase $(3.2 \mathrm{eV}$, tetragonal), rutile $(3.0 \mathrm{eV}$, tetragonal) and brookite (orthorhombic). Of the three phases, a combination of anatase and rutile phase $\mathrm{TiO}_{2}$ have been proven to be used as thin-film gas sensors ${ }^{8}$ and studies have also shown that, majorly, anatase phase $\mathrm{TiO}_{2}$ is a better gas sensor ${ }^{10}$ than rutiledominant $\mathrm{TiO}_{2}$. This is because anatase phase shows higher crystallinity, whereas rutile phase is more amorphous in nature; 
therefore, when used as a gas sensor, the anatase phase has higher mobility and trapping center for the gases than rutile phase $\mathrm{TiO}_{2}$.

Various studies have been conducted to analyze the properties of anatase over the years. Anatase is difficult to stabilize, and obtaining it depends on the preparation method and temperature used during the process. Keeping low temperature and easy control of morphology in mind, the sol-gel method is a favorable option as it is economical and much simpler in preparation compared to other methods. However, tuning the phase fraction in $\mathrm{TiO}_{2}$ thin films is hard to achieve in conventional sol-gel synthesis. ${ }^{11}$ Hence, the sol-gel method should be modified to synthesize $\mathrm{TiO}_{2}$ nanoparticles with the desired phase fractions. Room-temperature ionic liquids (RTILs) have gained much greater attention among researchers, ${ }^{\mathbf{1 2}}$ for their exceptional properties such as low vapor pressure ${ }^{13}$ and ability to decrease gel shrinkage during sol to gel transition, thus increasing the surface area of $\mathrm{TiO}_{2}$ NPs.

It is observed that ionic liquids induce structural organization at the nanoscale, which drives spontaneous ordering in nanomaterials. ${ }^{14-16}$ Several reports are available on different metal nanoparticles prepared using ionic liquids. ${ }^{\mathbf{1 7 - 2 1}}$ Ionic liquid assisted $\mathrm{TiO}_{2}$ nanoparticles have been synthesized and subsequently utilized for gold particle deposition and application in the CO oxidation. ${ }^{22}$ Using an ionic liquid (1-ethyl-3methylimidazoliumethylsulphate) [EMIM $]\left[\right.$ EtOSO $\left._{4}\right]$, nanoporous anatase form of $\mathrm{TiO}_{2}$ powder has been synthesized by non-hydrolytic sol-gel method. ${ }^{23}$ In the present study, $\mathrm{TiO}_{2}$ nanoparticles have been prepared using ionic liquids as phase tuning agents, and the effects of different ionic liquids with varying chain length on the $\mathrm{TiO}_{2}$ phases and gas sensing ability have been analyzed. The ionic liquids used in the study are given in Table 1.

Several researchers have started focusing on designing and enhancing the gas sensing ability of $\mathrm{TiO}_{2}$ NPs prepared using different techniques due to their high reactivity, chemical stability, non-toxicity, and low-cost commercial availability. The different approaches followed include adding different doping agents, ${ }^{24,25}$ varying the temperature during phase transition period, $^{26}$ and different working temperatures of the gas sensor. $^{27,28}$ The simultaneous adsorption and desorption of the gas on the surface of the thin film is the basic mechanism of gas sensing. As the reducing/oxidizing gas comes in contact with the surface of the gas sensor, chemisorption occurs on its surface and the resistance changes accordingly. This change in resistance depends on the surface morphology and the size and shape of the $\mathrm{TiO}_{2} \mathrm{NPs}^{29}$ Investigations have shown that $\mathrm{TiO}_{2} \mathrm{NPs}$ with

Table 1 List of RTILs used for this study

Symbol Full name

[EMIM] $\left[\mathrm{EtOSO}_{4}\right]$ 1-Ethyl-3-methylimidazolium ethyl sulphate

[EMIM] $\left[\mathrm{PF}_{6}\right]$ 1-Ethyl-3-methylimidazolium hexafluorophosphate [BMIM][Cl] [HMIM][Cl] 1-Butyl-3-methylimidazolium chloride [DMIM][Cl] 1-Decyl-3-methylimidazolium chloride nanotubular structure act as good gas sensors. ${ }^{30}$ Recently, research on gas sensing has also focused on enhancing the sensitivity of gas sensors at room temperature itself for the integration of gas sensors with CMOS technology, since the high operating temperature of the sensor leads to prolonged thermal treatment of CMOS materials including its substrate. ${ }^{30}$ However, the role of anatase and rutile phases in the gas sensing characteristics of $\mathrm{TiO}_{2}$ has not been reported thus far. ${ }^{29}$

In this study, sensitivity, selectivity, response and recovery time were the key components of thin-film gas sensors analyzed. Selectivity studies have been performed for various gases such as ammonia, ${ }^{31}$ ethanol, ${ }^{32}$ acetone, ${ }^{33}$ and toluene ${ }^{34}$ and the substances with appreciable sensitivity were chosen for this study. Experiments were repeated for different concentrations of the gas to study sensitivity and saturation concentration of the sensor. Our earlier reports suggested that sol-gel based synthesis of $\mathrm{TiO}_{2}$ without ionic liquids gives mixed anatase and rutile phases, but has sensitivity towards ethanol. ${ }^{32}$ In this study, ionic liquid has been used as a template to tune the phases, and experiments were also conducted to understand the relation of morphology and size of the NP with the gas sensing property of the prepared samples.

\section{Materials and methods}

\subsection{Materials}

The reagents used for the synthesis of $\mathrm{TiO}_{2}$ were titanium isopropoxide $\left[\mathrm{Ti}\left(\mathrm{OCH}\left(\mathrm{CH}_{3}\right)_{2}\right)_{4}\right]$ (CAS no. 546-68-9), 2-propanol, nitric acid $\left(\mathrm{HNO}_{3}\right)$ and ionic liquids EMIM ethyl sulphate (CAS no. 342573-75-5), EMIM hexafluorophosphate (CAS no. 15537119-0), BMIM chloride (CAS no. 79917-90-1), HMIM chloride (CAS no. 171058-17-6) and DMIM chloride (CAS no. 155371-19$0)$. Titanium isopropoxide, 2-propanol, nitric acid and ionic liquids were all purchased from Sigma-Aldrich with 99.9\% purity. Doubly distilled water was utilized for all processes.

\subsection{Method}

The procedure used for the preparation of $\mathrm{TiO}_{2} \mathrm{NP}$ was the solgel method. This method was previously reported. ${ }^{35}$ The precursor solution used was a mixture of $5 \mathrm{ml}$ TTIP and $20 \mathrm{ml}$ propanol. Nitric acid was used as the catalyst for hydrolysis and was added dropwise, in addition to the deionized water, after an hour to the precursor solution, which was constantly stirred with a magnetic stirrer at $80{ }^{\circ} \mathrm{C}$ for 6 hours. For each sample, distilled water or the respective ionic liquid was added two hours into the stirring process. After the stirring, the precursor mixture was calcined in a muffle furnace at $450{ }^{\circ} \mathrm{C}$ for 5 hours and allowed to cool to room temperature slowly. Finally, the powder was collected and transferred to a pestle-mortar and ground to a fine powder that was used for further investigation. Fig. 1 depicts the preparation process.

The sensor elements were prepared by depositing the prepared $\mathrm{TiO}_{2}$ NPs as thin films using the dip coating process. The solution for the dip coating process was prepared by mixing $\mathrm{TiO}_{2}$ and propanol at a concentration of $1 \mathrm{mg} \mathrm{ml}^{-1}$. The NP dispersed solution was prepared for all five samples prepared 


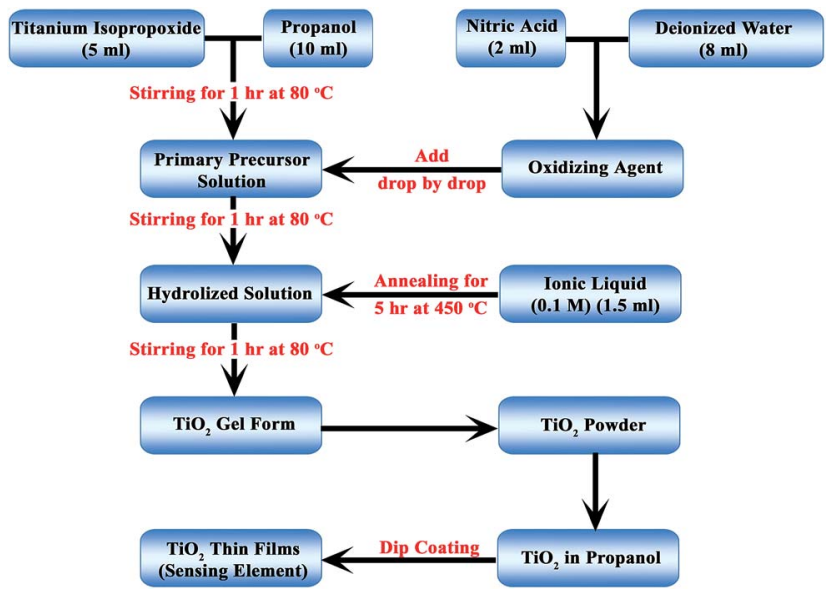

Fig. 1 Flow diagram of preparation process.

with different ionic liquids. These solutions were coated onto glass plates $(45 \times 13 \times 1 \mathrm{~mm})$. Before dip coating, the glass plates were cleaned with chromic acid and doubly distilled water. This dipping process was repeated five times. The dipping process was carried out at room temperature. After the dip coating, the samples were dried at $30{ }^{\circ} \mathrm{C}$ to remove the solvent from the film.

\subsection{Characterization of prepared $\mathrm{TiO}_{2} \mathrm{NPs}$}

$\mathrm{X}$-Ray diffraction (Rigaku Ultima III, Japan) with $\mathrm{Cu} \mathrm{K} \alpha_{1}(1.5406$ $\AA$ A) was used to investigate the crystallographic nature of the NPs and to identify the phases present in the NPs. The intensity of the diffracted X-ray was plotted as a function of diffraction angle $(2 \theta)$. The $2 \theta$ range used was $20^{\circ}$ to $80^{\circ}$. Contact angle measurement was performed using a contact angle measurement setup (Model no. HO-IAD-CAM-01A, Holmarc, India), and the analysis was done to show the level of wettability of the thinfilm surface. A UV-visible spectrophotometer (Shimadzu, Japan) was used to determine the energy band gaps of the prepared samples. The surface morphology and distribution of NPs were analyzed by scanning electron microscopy (FEI Quanta 600 FEG, USA) and transmission electron microscopy (Philips CM 200, Netherlands). TEM analyses were conducted at an acceleration voltage of $120 \mathrm{keV}$. The surface roughness values were determined from atomic force microscopy (AFM) analysis performed using the Agilent 5500 model. The roughness values determined were compared with the gray code roughness values determined from SEM images obtained using ImageJ.

\subsection{Gas sensing experiment}

The chemicals used for gas sensing studies were purchased from Merck, India, and were vaporized using a high temperature flash vaporizer. An air tight chamber with a capacity of 6 litres with solenoid controlled gas/vapor inlet and outlet valves was used for sensing characterizations of the prepared thin films. The film (having the size of $20 \mathrm{~mm} \times 10 \mathrm{~mm}$ ) was placed on the sample stage and silver paste was used on the edges of the film surface in order to ensure ohmic contact between the samples and

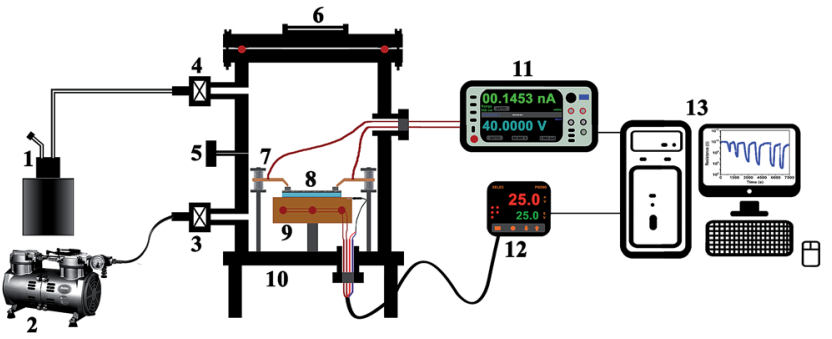

Fig. 2 Schematic diagram of the gas/vapor sensing setup (1) flash evaporator with liquid injection arrangement, (2) vacuum pump, (3) gas out solenoid valve, (4) gas in valve, (5) air flushing valve, (6) view port, (7) spring loaded contacts, (8) sensing element, (9) sample stage with ceramic heater and thermocouple, (10) air tight chamber with electrical feedthroughs, (11) Keithley 2450 digital interactive source meter, (12) Selec PID-500 auto-tuning temperature controller with RS-485 communication, and (13) computer running LabVIEW-based sensing measurement and control module.

probes. The working temperature of the sensor was maintained by a ceramic resistive heater connected to the sample stage and was monitored and controlled with a PID temperature controller (Selec PID-500-2-0-04, India). The gas sensing experiments were performed by keeping the sensor operating temperature at room temperature $\left(T_{\mathrm{w}}=25{ }^{\circ} \mathrm{C}\right)$. The resistance of the sensor element was measured using a Keithley 2450 interactive digital source measure unit for every 0.5 seconds by sourcing the voltage and measuring the current. The entire sensing setup was controlled through a computer running a GUI developed in LabVIEW. The schematic of the gas/vapor sensing setup developed for the present study is shown in Fig. 2.

The resistance in ambient air was taken as the base resistance and once it stabilized, the gas was injected through the gas inlet valve and the change in the resistance was used to calculate the sensitivity $(S)$ of the thin-film gas sensor using eqn (1). ${ }^{36}$

$$
S=R_{\mathrm{a}} / R_{\mathrm{g}}
$$

where $R_{\mathrm{a}}$ and $R_{\mathrm{g}}$ are the resistance in air and in gas, respectively.

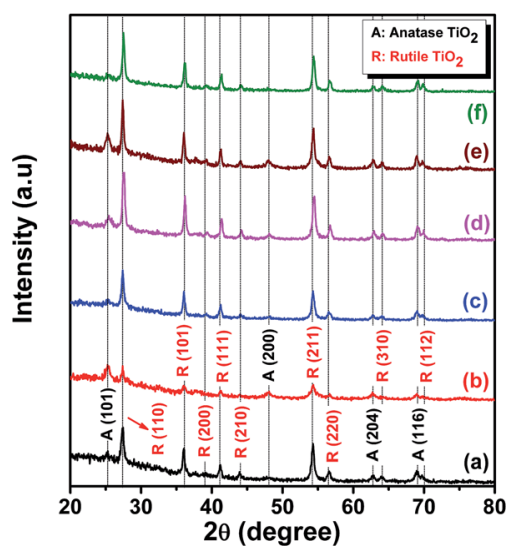

Fig. 3 Indexed X-ray diffraction patterns of $\mathrm{TiO}_{2}$ samples (a) without ionic liquid, (b) with $[E M I M]\left[\mathrm{PF}_{6}\right]$, (c) with $[\mathrm{EMIM}]\left[\mathrm{EtOSO}_{4}\right]$, (d) with [BMIM][Cl], (e) with [HMIM][Cl], and (f) with [DMIM][Cl]. 
The concentration of the testing gas injected was calculated using relation $(2) \cdot{ }^{37}$

$$
C_{\mathrm{ppm}}=\frac{\delta \times V \times R \times T}{M \times P_{\mathrm{b}} \times V_{\mathrm{b}}} \times 10^{6}
$$

where $\delta$ is the density of testing gas (in $\mathrm{g} \mathrm{ml}^{-1}$ ), $V$ is the volume of the injected test gas (in $\mu \mathrm{l}), R$ is the universal gas constant $(8.415 \mathrm{~J}$ $\mathrm{mol}^{-1} \mathrm{~K}^{-1}$ ), $T$ is the sensor temperature (in $\mathrm{K}$ ), $M$ is the molecular weight of the testing gas (in $\mathrm{g} \mathrm{mol}^{-1}$ ), $P_{\mathrm{b}}$ is the chamber pressure, and $V_{\mathrm{b}}$ is the volume of the chamber (in litres).

\section{Results and discussion}

\subsection{Characterization}

The physical properties of $\mathrm{TiO}_{2}$ were analyzed by different techniques. UV-Vis spectroscopy was used to determine the

Table 2 Phase percentage and mean crystallite size of samples

\begin{tabular}{|c|c|c|c|}
\hline Sample & $\begin{array}{l}\% \\
\text { anatase }\end{array}$ & $\begin{array}{l}\% \\
\text { rutile }\end{array}$ & $\begin{array}{l}\text { Mean crystallit } \\
\text { size (nm) }\end{array}$ \\
\hline $\mathrm{TiO}_{2}$ without ionic liquid & 14 & 86 & 15.4 \\
\hline $\mathrm{TiO}_{2}$ with $[\mathrm{EMIM}]\left[\mathrm{PF}_{6}\right](0.1 \mathrm{M})$ & 58 & 42 & 12.6 \\
\hline $\mathrm{TiO}_{2}$ with $[\mathrm{EMIM}]\left[\mathrm{EtOSO}_{4}\right](0.1 \mathrm{M})$ & 15 & 85 & 10.9 \\
\hline $\mathrm{TiO}_{2}$ with $[\mathrm{BMIM}][\mathrm{Cl}](0.1 \mathrm{M})$ & 13 & 87 & 14.1 \\
\hline $\mathrm{TiO}_{2}$ with [HMIM] [Cl] $(0.1 \mathrm{M})$ & 30 & 70 & 13.3 \\
\hline $\mathrm{TiO}_{2}$ with [DMIM][Cl] $(0.1 \mathrm{M})$ & 5 & 95 & 25.6 \\
\hline
\end{tabular}

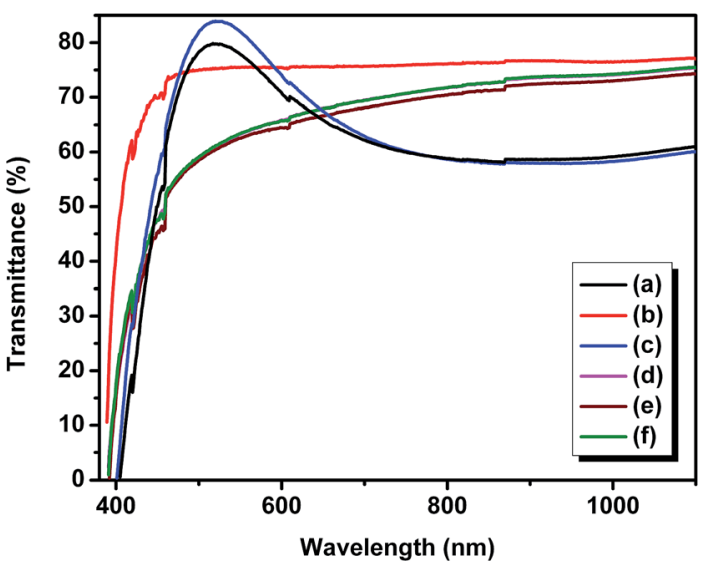

Fig. 4 UV-Vis spectra of $\mathrm{TiO}_{2}$ thin films (a) without ionic liquid, (b) with $[E M I M]\left[P F_{6}\right]$, (c) with $[E M I M]\left[E_{\text {ESOSO }}\right]$, (d) with $[B M I M][C l]$, (e) with $[\mathrm{HMIM}][\mathrm{Cl}]$, and (f) with [DMIM][Cl].

Table 3 Bandgap energy of $\mathrm{TiO}_{2}$ samples

\begin{tabular}{ll}
\hline Sample & Band gap (eV) \\
\hline $\mathrm{TiO}_{2}$ without ionic liquid & 3.01 \\
$\mathrm{TiO}_{2}$ with [EMIM][PF$](0.1 \mathrm{M})$ & 3.21 \\
$\mathrm{TiO}_{2}$ with [EMIM][EtOSO $](0.1 \mathrm{M})$ & 3.02 \\
$\mathrm{TiO}_{2}$ with [BMIM][Cl] $(0.1 \mathrm{M})$ & 3.07 \\
$\mathrm{TiO}_{2}$ with [HMIM][Cl] $(0.1 \mathrm{M})$ & 3.15 \\
$\mathrm{TiO}_{2}$ with [DMIM][Cl] $(0.1 \mathrm{M})$ & 2.99
\end{tabular}

energy band gap, whereas XRD analysis was used to identify the phase and the crystallite size. The contact angle measurement showed whether the prepared thin films are hydrophobic or hydrophilic in nature, which is very important for a thin-film gas sensor when used commercially. SEM and TEM analyses show morphology and particle size distribution of the $\mathrm{TiO}_{2} \mathrm{NPs}$.

3.1.1 X-ray diffraction analysis. XRD patterns of the samples were analyzed to identify the anatase and rutile phases and to calculate the percentage of each phase present. From the XRD patterns, it was inferred that the samples prepared with different ionic liquids show peaks of different intensities at different angles, proving that the addition of ionic liquids has significantly changed crystallographic planes and caused variation in phases. The patterns were indexed and were in complete agreement with standard JCPDS Ref (00-021-1272) and

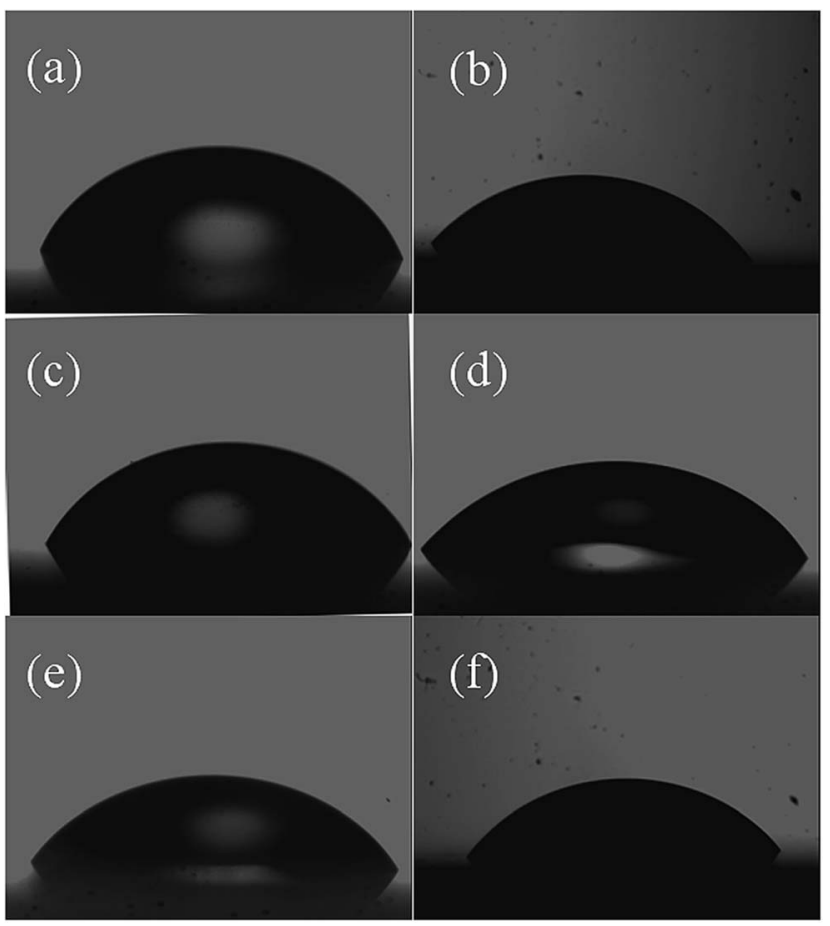

Fig. 5 Contact angle measurement performed on $\mathrm{TiO}_{2}$ thin-film samples prepared using $\mathrm{TiO}_{2}$ powders prepared (a) without ionic liquid, (b) with [EMIM] $\left[\mathrm{PF}_{6}\right]$, (c) with $[\mathrm{EMIM}]\left[\mathrm{EtOSO}_{4}\right]$, (d) with [BMIM] $[C l]$, (e) with [HMIM][Cl], and (f) with [DMIM][Cl].

Table 4 Calculated values of the work of adhesion

\begin{tabular}{llll}
\hline & $\begin{array}{l}\text { Contact } \\
\text { angle }(\theta)\left( \pm 1^{\circ}\right)\end{array}$ & $\begin{array}{l}\text { Work of } \\
\text { adhesion } \\
\left(\mathrm{mJ} \mathrm{m}^{-2}\right)( \pm 1)\end{array}$ & $\begin{array}{l}\text { RMS } \\
\text { roughness } \\
(\mathrm{nm})\end{array}$ \\
\hline $\mathrm{TiO}_{2}$ without ionic liquid & 59.9 & 109.3 & 114.7 \\
$\mathrm{TiO}_{2}$ with [EMIM][ $\left.\mathrm{PF}_{6}\right]$ & 51.1 & 118.5 & 108.1 \\
$\mathrm{TiO}_{2}$ with [EMIM][EtOSO & 67.9 & 100.2 & 133.7 \\
$\mathrm{TiO}_{2}$ with [BMIM][Cl] & 50.8 & 118.8 & 99.7 \\
$\mathrm{TiO}_{2}$ with [HMIM][Cl] & 52.5 & 117.1 & 114.7 \\
$\mathrm{TiO}_{2}$ with [DMIM][Cl] & 52.9 & 116.7 & 120.7
\end{tabular}



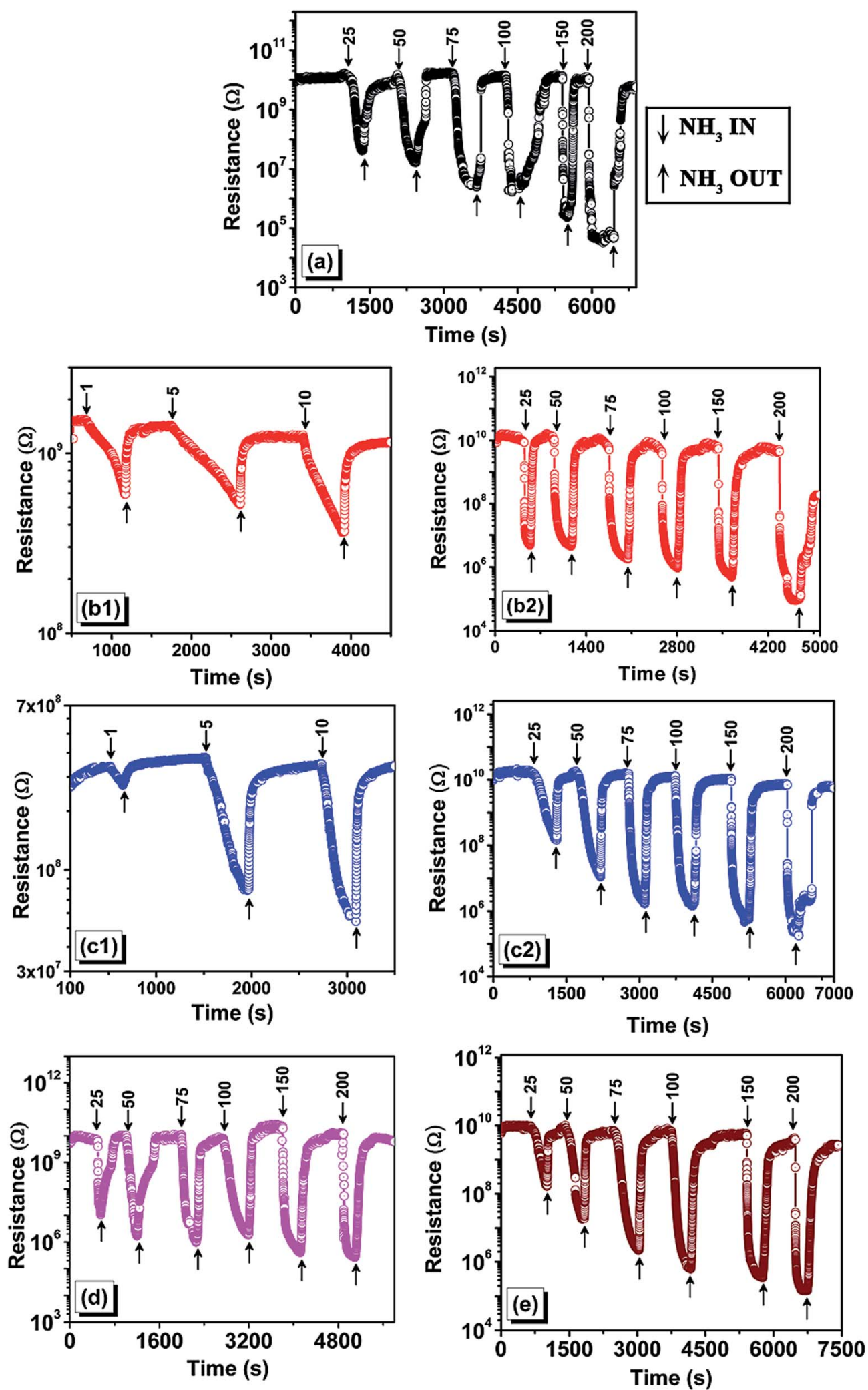

Fig. 6 Sensing response plots for ammonia gas sensing of $\mathrm{TiO}_{2}$ samples prepared (a) without ionic liquid, (b) with [EMIM][PF 6 , (c) with [EMIM] $\left[\mathrm{EtOSO}_{4}\right],(\mathrm{d})$ with $[\mathrm{BMIM}][\mathrm{Cl}]$, and $(\mathrm{e})$ with $[\mathrm{HMIM}][\mathrm{Cl}$. Low ppm sensing results are given separately for samples b and c as (b1) and (c1). The numbers indicated on the plot are the concentrations of gas injected (in ppm). 
Ref (01-084-1284) for anatase and rutile phases, respectively. Fig. 3 shows the XRD patterns of the six prepared samples.

Each sample showed different percentage of anatase and rutile phases, which is calculated using eqn (3)

$$
W_{\mathrm{R}}=\frac{I_{\mathrm{R}}}{0.884 I_{\mathrm{A}}+I_{\mathrm{R}}}
$$

where $W_{\mathrm{R}}$ is the fraction of rutile, $I_{\mathrm{R}}$ is intensity concentration of rutile and $I_{\mathrm{A}}$ is intensity concentration of anatase.

Table 2 shows the result of phase percentage of each sample and that the addition of ionic liquids helps in phase tuning of $\mathrm{TiO}_{2}{ }^{38}$ This is the driving point to analyze the samples for gas sensing characteristics. Samples prepared using ionic liquid [EMIM $]\left[\mathrm{PF}_{6}\right]$ were anatase phase (58\%) dominant, whereas other ionic liquids were rutile phase dominant. This could be due to the self-assembly of ionic liquids in the sol-gel, leading to phase changes in $\mathrm{TiO}_{2}$. Such self-organization of ionic liquids controlling the size and morphology of different nanoparticles have been reported..$^{39,40}$

The mean size of nanocrystallites was calculated from XRD data using Scherrer's formula given by eqn (4)

$$
D=\frac{K \lambda}{\beta \cos \theta}
$$

where $K$ is the Scherrer constant, $\lambda$ the $\mathrm{X}$-ray wavelength, $\beta$ is the peak width of half maximum, and $\theta$ is the Bragg angle. Table 2 also shows the particle size of $\mathrm{TiO}_{2}$ samples.

The mean crystallite size in comparison with the phases of the respective sample clearly indicated that rutile-dominant samples have a larger size. This phenomenon agrees with the more crystalline and amorphous nature of anatase and rutile, respectively, as discussed.

3.1.2 UV-Vis spectroscopy. The band gap energies $\left(E_{\mathrm{g}}\right)$ of $\mathrm{TiO}_{2}$ nanoparticulate thin films were obtained from UV-Vis spectra (shown in Fig. 4) and were calculated using the Tauc plot. ${ }^{41}$ The bandgap energies for different $\mathrm{TiO}_{2}$ samples are tabulated in Table 3.

The reported band gap of rutile and anatase $\mathrm{TiO}_{2}$ is 3.0 and $3.2 \mathrm{eV}$, respectively. ${ }^{38}$ From the table, it can be proved that the values of the prepared samples agree with the standard band gap values.

3.1.3 Contact angle. $\mathrm{TiO}_{2} \mathrm{NP}$ powder was dispersed in propanol and dip coated on substrate surface. Wettability of $\mathrm{TiO}_{2}$ film surface was checked for each sample. In the case of complete wetting (spreading), the contact angle was $0^{\circ}$. Between

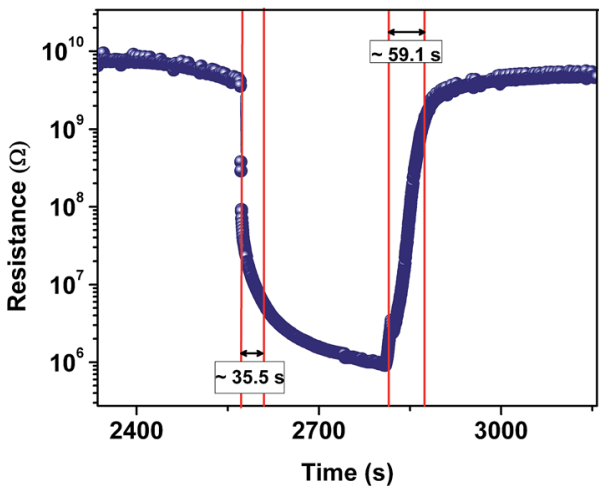

Fig. 7 Response and recovery curve of $\mathrm{TiO}_{2}$ samples prepared with [EMIM] $\left[\mathrm{PF}_{6}\right]$ for $100 \mathrm{pm}$ of ammonia.

\begin{tabular}{|c|c|c|}
\hline Samples & Response time (s) & Recovery time (s) \\
\hline $\mathrm{TiO}_{2}$ without ionic liquid & 130 & 372 \\
\hline $\mathrm{TiO}_{2}$ with $[\mathrm{EMIM}]\left[\mathrm{PF}_{6}\right]$ & 35.5 & 59 \\
\hline $\mathrm{TiO}_{2}$ with $[\mathrm{EMIM}]\left[\mathrm{EtOSO}_{4}\right]$ & 85.3 & 64 \\
\hline $\mathrm{TiO}_{2}$ with $[\mathrm{BMIM}][\mathrm{Cl}]$ & 145 & 181.5 \\
\hline $\mathrm{TiO}_{2}$ with $[\mathrm{HMIM}][\mathrm{Cl}]$ & 235 & 56.5 \\
\hline
\end{tabular}

Table 6 Comparison of response and recovery time

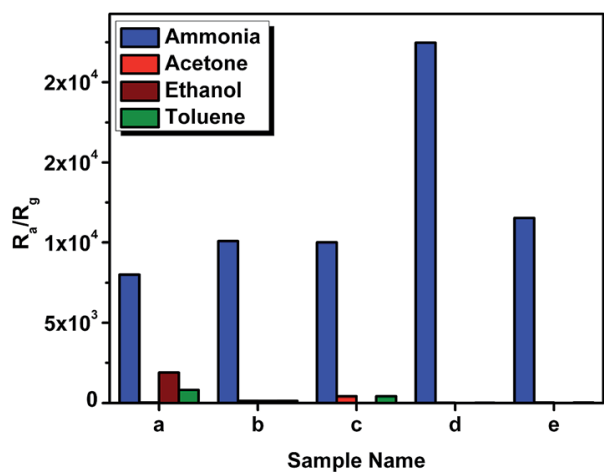

Fig. 8 Selectivity graph of all $\mathrm{TiO}_{2}$ samples for 100 ppm of different target gases.

$0^{\circ}$ and $90^{\circ}$, the solid was wettable, and above $90^{\circ}$, it was not wettable. ${ }^{42}$ Fig. 5 shows contact angle measurements of all thin films of $\mathrm{TiO}_{2}$ NPs. The work of adhesion $(W)$ is the work that

Table 5 Comparative results of sensitivity measurement of different $\mathrm{TiO}_{2}$ samples

\begin{tabular}{|c|c|c|c|c|c|c|c|c|c|}
\hline Samples & 1 & 5 & 10 & 25 & 50 & 75 & 100 & 150 & 200 \\
\hline $\mathrm{TiO}_{2}$ without ionic liquid & - & 一 & - & 428.3 & 906.4 & 6106.6 & 8013.5 & 60117.9 & 165604.8 \\
\hline $\mathrm{TiO}_{2}$ with $[\mathrm{EMIM}]\left[\mathrm{PF}_{6}\right]$ & 2.5 & 2.7 & 3.4 & 3405.4 & 3423.8 & 6702.1 & 10080.8 & 17253.8 & 65100.2 \\
\hline $\mathrm{TiO}_{2}$ with $[\mathrm{EMIM}]\left[\mathrm{EtOSO}_{4}\right]$ & 1.3 & 4.8 & 6 & 120.5 & 1602.1 & 9637.1 & 9999.3 & 17163.4 & 29458 \\
\hline $\mathrm{TiO}_{2}$ with $[\mathrm{BMIM}][\mathrm{Cl}]$ & - & - & - & 828.8 & 5701.7 & 11759.3 & 22472.1 & 35477.3 & 26148 \\
\hline $\mathrm{TiO}_{2}$ with $[\mathrm{HMIM}][\mathrm{Cl}]$ & 一 & 一 & - & 64.52 & 495.02 & 3326.9 & 11530.5 & 14951 & 54865.5 \\
\hline $\mathrm{TiO}_{2}$ with $[\mathrm{DMIM}][\mathrm{Cl}]$ & - & - & - & - & - & - & - & - & - \\
\hline
\end{tabular}

Sensitivity $\left(R_{\mathrm{a}} / R_{\mathrm{g}}\right)$ at different $\mathrm{ppm}$ 
must be done to separate two adjacent phases 1 and 2 of a liquid-liquid or liquid-solid phase boundary from one another. In other words, it is the energy released in the process of wetting. The unit of work of adhesion is $\mathrm{J} \mathrm{m}^{-2}$. For a liquidsolid phase boundary, the work of adhesion $(W)$ can be calculated from the contact angle $\theta$ using the Young-Dupré equation (eqn (5)), and the values are tabulated in Table 4.

$$
W=\sigma(1+\cos \theta)
$$

where $\sigma$ denotes surface tension of water.

It can be seen from Table 4 that addition of ionic liquids effectively varies the contact angle and work of adhesion of $\mathrm{TiO}_{2}$ samples. The films were subjected to AFM analysis to understand the role of surface roughness in determining contact angle and hence the quality of sensing. The obtained RMS surface roughness for all samples is listed in Table 4. $\mathrm{TiO}_{2}$ prepared using $[\mathrm{BMIM}][\mathrm{Cl}]$ and [EMIM] $\left[\mathrm{PF}_{6}\right]$ show lower surface roughness and higher work of adhesion. It can be seen that the surface roughness is lower for samples with
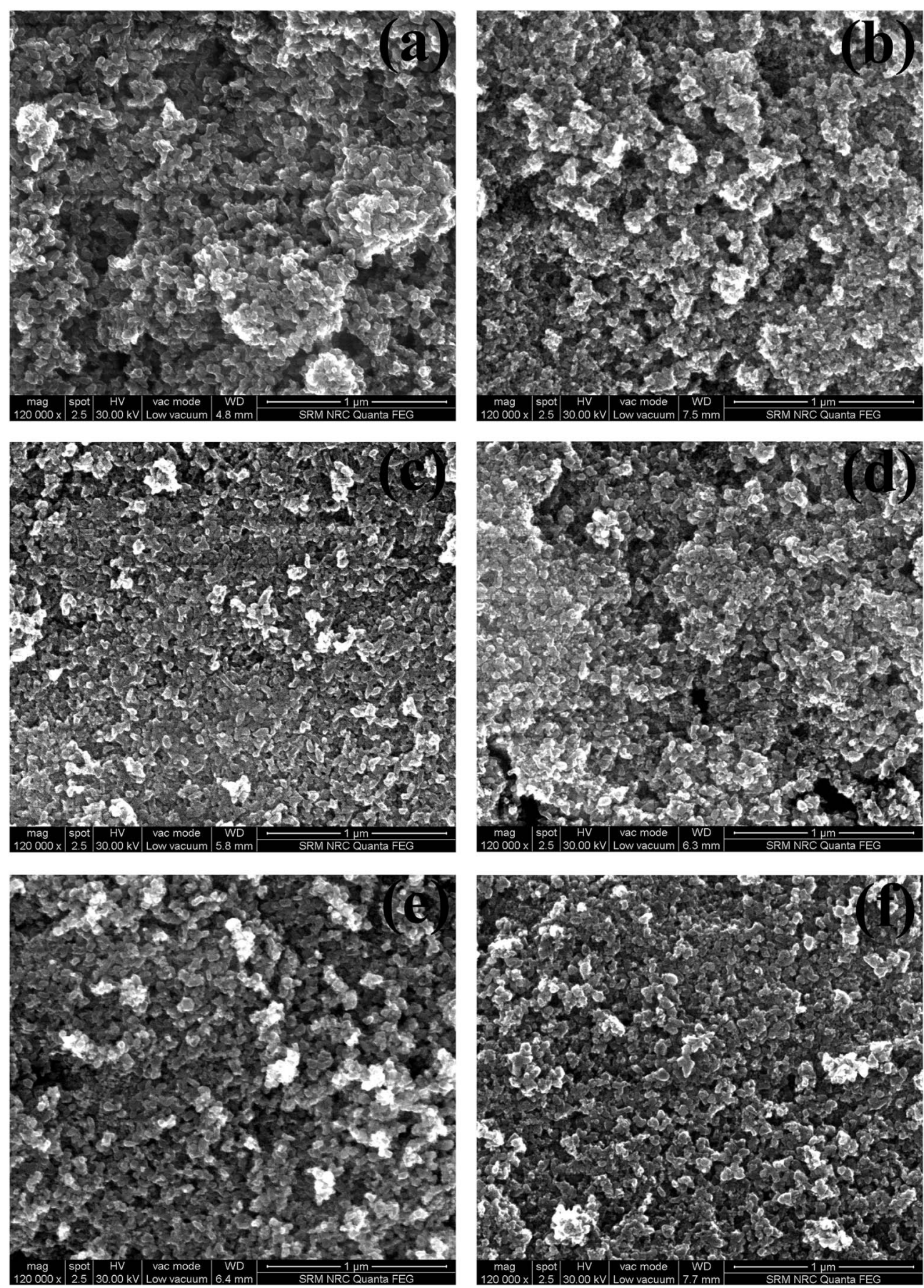

Fig. $9 \mathrm{SEM}$ micrographs of all $\mathrm{TiO}_{2}$ thin films (a) without ionic liquid, (b) with [EMIM][PF 6 , (c) with [EMIM][EtOSO 4 , (d) with [DMIM][Cl], (e) with [BMIM][Cl], and (f) with [HMIM][Cl]. 
higher work of adhesion and thus can be used for sensing analysis. Such increase in work of adhesion due to low surface roughness has been reported in gold nano thin films. ${ }^{43}$

\subsection{Gas sensing studies}

3.2.1. Sensitivity. The gas sensitivity of a thin film is usually measured by observing the change in resistance when exposed to a particular gas. As chemisorption occurs on the surface of the thin film, the resistance changes and the normalized change in resistance is called the sensitivity of a gas sensor. Previous reports published shows that gas sensing was performed at a high working temperature of about $400{ }^{\circ} \mathrm{C},{ }^{26}$ but in the present study, gases such as ammonia, acetone, ethanol and toluene were all sensed at room temperature $\left(25^{\circ} \mathrm{C}\right)$ in order to check room temperature sensitivity of the sensor, which reduces the fabrication cost of the sensor element with microheater arrangement. Fig. 6 shows ammonia gas sensing of $\mathrm{TiO}_{2}$ with different ionic liquids. Table 5 displays the results of comparative sensitivity measurement of all the prepared samples at different concentrations of ammonia.

It is inferred from the results that only the samples prepared with short chain cation ionic liquids were able to detect the ammonia gas at lower concentrations. Furthermore, the longer cation chain ionic liquid samples and samples without ionic liquid showed higher sensitivity at higher concentrations but did not sense the gas at lower concentrations. The morphology and mean crystallite size of the sample play a key role in the ability to sense gases; ${ }^{4}$ the highest sensitivity sample was the same NPs with the highest anatase phase. The sample $\mathrm{TiO}_{2}$ with $[\mathrm{DMIM}][\mathrm{Cl}]$ did not exhibit sensing property for any of the tested gases in the present study. Hence, it is again proven that anatase-dominant $\mathrm{TiO}_{2}$ thin films are better gas sensors, while the rutile-dominant sample $\left(\mathrm{TiO}_{2}\right.$ with $\left.[\mathrm{DMIM}][\mathrm{Cl}]\right)$ could not sense any gases.

3.2.2 Response and recovery time. An ideal gas sensor should have minimum response and recovery time. Fig. 7 depicts the response and recovery time of $\mathrm{TiO}_{2}$ NPs with [EMIM] $\left[\mathrm{PF}_{6}\right]$ by fixing the ppm of ammonia to $100 \mathrm{ppm}$ (medium concentration of sensor range), which was injected into the chamber. The response time, the time taken to stably detect the gas and recovery time, the time taken to return to the base resistance when the gas leaves the chamber, were determined.

A comparative study of the recovery and response time of all prepared samples (Table 6) at $100 \mathrm{ppm}$ of ammonia clearly confirms that the sample prepared with short chain ionic liquids have a faster response to gas sensing.

3.2.3 Selectivity. Selectivity is the ability of sensor to detect a particular gas; in this case, only four gases were detected by the prepared $\mathrm{TiO}_{2}$ sample, namely ammonia, acetone, ethanol and toluene. These gases were considered by performing the response analysis for various gases. A comparative histogram for the selectivity of all $\mathrm{TiO}_{2}$ samples at 100 ppm of each gas is shown in Fig. 8.

It is observed that the sol-gel prepared $\mathrm{TiO}_{2}$ can be a good candidate for a sensor element in gas sensors for ammonia

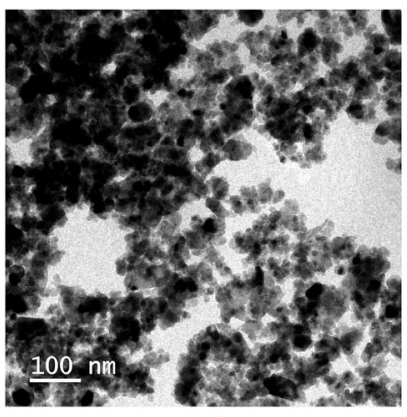

(a)

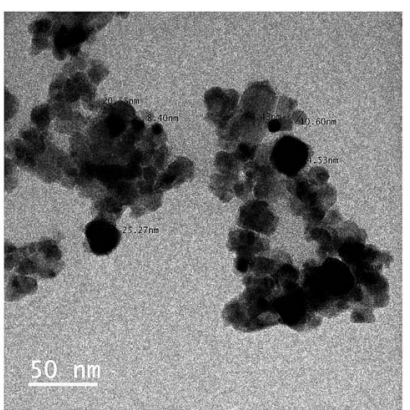

(b)
Fig. 10 TEM images of $\mathrm{TiO}_{2}$ samples prepared with [EMIM][PF 6 ; (a) lower magnification, and (b) higher magnification with particle size measurement.

sensing, and on adding ionic liquids, the performance can be further enhanced. All samples showed highest selectivity towards the sensing of ammonia.

\subsection{Morphology studies}

On understanding the gas sensing of $\mathrm{TiO}_{2}$ NPs, the morphology and the distribution of particles become highly important. Hence, SEM and TEM analyses were conducted for the samples.

3.3.1 SEM. SEM images of thin films of $\mathrm{TiO}_{2}$ samples are provided in Fig. 9. It can be seen that the ionic liquid makes the surface morphology of the samples more uniform than that of the control. This surface phenomenon can be correlated with the percentage of phases present in the samples: the higher the anatase phase the greater the crystallinity and uniformity in morphology.

3.3.2 TEM. TEM analyses were conducted to understand particle distribution and estimate the size of the particle, which was then compared with crystallite size obtained from XRD. Fig. 10(a) and (b) were the TEM images obtained for the $\mathrm{TiO}_{2}$ sample prepared with [EMIM] $\left[\mathrm{PF}_{6}\right]$. Particles were distributed evenly (Fig. 10(a)) and spherical nanoparticles were formed in two size ranges; the smaller particles had an average size of $12 \mathrm{~nm}$, while the larger particles had an average size of $25 \mathrm{~nm}$. The crystallite size was obtained from XRD analysis and on comparing values from both TEM (Fig. 10(b)) and XRD, almost the same values were obtained.

\section{Conclusion}

With an increase in the need to monitor ammonia in our environment, $\mathrm{TiO}_{2}$-based gas sensors were studied. Six different phase-tuned $\mathrm{TiO}_{2}$ thin films were prepared and studied for application as a gas sensor. The thin films were prepared by dip coating process and their degree of wettability was studied by measuring contact angle and then calculating the work of adhesion. The gas sensing behavior of the film was tested at room temperature. The thin films showed the best response and selectivity towards ammonia among the gases tested. It was observed that the sol-gel prepared $\mathrm{TiO}_{2}$ acts as an excellent gas sensor, and on adding ionic liquids, this property is further 
enhanced. On comparing sensitivity, selectivity, response time and recovery time of all the samples, we inferred that the $\mathrm{TiO}_{2}$ sample with $\mathrm{EMIM} \cdot \mathrm{PF}_{6}$ displayed the best gas sensing characteristics; moreover, it had the highest anatase phase percentage. Hence, we concluded that anatase-dominant samples displayed better gas sensing. $\mathrm{TiO}_{2}$ with $[\mathrm{DMIM}][\mathrm{Cl}]$ sample, which was rutile dominant, did not show any sensing characteristics. On comparing the structure of ionic liquids and gas sensing ability of the samples, it was inferred that short chain cation ionic liquids with highest anatase percentage proved to be good gas sensors and as the chain length increased, the sensing character decreased.

\section{Acknowledgements}

Author K. S. thanks Department of Science and Technology, Govt of India, for the Inspire Faculty Award (IFA13-PH-82, Dy. No. 108 Dt. 8.1.2014). Author N. M. thanks DST-SERB for financial assistance through the project numbered (YSS/2015/ 000954, Dy. No. SERB/F/5187/2016-17 Dt. 18.10.2016). Author K. J. thanks DST-SERB for financial assistance through the project numbered "SB/FTP/PS-038/2013" for the sensing setup development.

\section{References}

1 F. Paulot, D. J. Jacob, R. W. Pinder, J. O. Bash, K. Travis and D. K. Henze, J. Geophys. Res.: Atmos., 2014, 7, 4343.

2 R. F. Griffiths and L. C. Megson, Atmos. Environ., 1984, 61, 195.

3 M. Arauzo and M. Valladolid, Water Res., 2003, 11, 2547.

4 Toxicological Profile for Ammonia, Agency for Toxic Substances and Disease Registry (ATSDR), 2004, https:// www.atsdr.cdc.gov/ToxProfiles/TP.asp?id=11\&tid $=2$.

5 W. Meng, L. Dai, W. Meng, H. Zhou, Y. Li, Z. He and L. Wang, Sens. Actuators, B, 2017, 240, 962.

6 M. Batzill and U. Diebold, Phys. Chem. Chem. Phys., 2007, 9(19), 2307.

7 G. Zhang and M. Liu, Sens. Actuators, B, 2000, 69, 144.

8 C. Garzella, E. Comini, E. Tempesti, C. Frigeri and G. Sberveglieri, Sens. Actuators, B, 2000, 68, 189.

9 A. Fujishima, T. N. Rao and D. A. Tryk, J. Photochem. Photobiol., C, 2000, 1, 1.

10 H. Tang, K. Prasad, R. Sanjines and F. Levy, Sens. Actuators, B, 1995, 26, 71.

11 F. Shi, Y. Ma, J. Ma, P. Wang and W. Sun, J. Membr. Sci., 2013, 427, 269.

12 K. Sankaranarayanan and M. Kalaiyarasi, Int. J. Nanosci., 2014, 13, 1450006.

13 T. Welton, Chem. Rev., 1999, 99, 2083.

14 C. M. Corrêa, M. A. Bizeto and F. F. Camilo, J. Nanopart. Res., 2016, 18, 132.

15 J. Dupont, J. Braz. Chem. Soc., 2004, 15, 341.

16 J. Dupont and J. D. Scholten, Chem. Soc. Rev., 2010, 39, 1780.

17 Y. Zhou and M. Antonietti, J. Am. Chem. Soc., 2003, 125, 14960.
18 J. Krämer, E. Redel, R. Thomann and C. Janiak, Organometallics, 2008, 27, 1976.

19 J. Dupont and P. A. Z. Suarez, Phys. Chem. Chem. Phys., 2006, 8, 2441.

20 K. Ueno, H. Tokuda and M. Watanabe, Phys. Chem. Chem. Phys., 2010, 12, 1649.

21 M. A. Neouze, J. Mater. Chem., 2010, 20, 9593.

22 R. S. Avellaneda, S. Ivanova, O. Sanz, F. Romero-Sarria, M. A. Centeno and J. A. Odriozola, Appl. Catal., B, 2009, 1, 140.

23 Y. L. Verma, M. P. Singh and R. K. Singh, Mater. Lett., 2012, 86, 73 .

24 A. Charanpahari, S. S. Umare and R. Sasikala, Appl. Surf. Sci., 2013, 282, 408.

25 Y. Horie, T. Watanabe, M. Deguchi, D. Asakura and T. Nomiyama, Electrochim. Acta, 2013, 105, 394.

26 K. S. Yoo, T. G. Lee and J. Kim, Microporous Mesoporous Mater., 2005, 84, 211.

27 S. Akbar, P. Dutta and C. Lee, Int. J. Appl. Ceram. Technol., 2006, 3, 302.

28 W. C. Tian, Y. H. Ho, C. H. Chen and C. Y. Kuo, Sensors, 2013, 13, 865.

29 H.-M. Lin, C.-H. Keng and C.-Y. Tung, Nanostruct. Mater., 1997, 9, 747.

30 F. Udrea, S. Santra, P. K. Guha, S. Z. Ali, J. A. Covington, W. I. Milne, J. W. Gardner and S. Maeng, AIP Conf. Proc., 2009, 1137, 19.

31 B. Karunagaran, P. Uthirakumar, S. J. Chung, S. Velumani and E.-K. Suh, Mater. Charact., 2007, 58, 680.

32 R. Pandeeswari, R. K. Karn and B. G. Jeyaprakash, Sens. Actuators, B, 2014, 194, 470.

33 N. Chen, Y. Li, D. Deng, X. Liu, X. Xing, X. Xiao and Y. Wang, Sens. Actuators, B, 2017, 238, 491.

34 Y. Liu, L. Wang, H. Wang, M. Xiong, T. Yang and G. S. Zakharova, Sens. Actuators, B, 2016, 236, 529.

35 R. K. Karn and O. N. Srivastava, Int. J. Hydrogen Energy, 1998, 23, 439.

36 G. Sakai, N. Matsunaga, K. Shimanoe and N. Yamazoe, Sens. Actuators, B, 2001, 80, 125.

37 R. Pandeeswari and B. G. Jeyaprakash, Sens. Actuators, B, 2014, 195, 206.

38 H. Tang, K. Prasad, R. Sanjines and P. Schmid, J. Appl. Phys., 1994, 75, 2042.

39 V. Mansfeldova, B. Laskova, H. Krysova, M. Zukalova and L. Kavan, Catal. Today, 2014, 230, 85.

40 T. Gutel, J. Garcia-Antõn, K. Pelzer, K. Philippot, C. C. Santini, Y. Chauvin, B. Chaudret and J. Basset, Mater. Chem., 2007, 17, 3290.

41 A. Dolgonosa, T. O. Masona and K. R. Poeppelmeier, J. Solid State Chem., 2016, 240, 43.

42 L. Gao and T. J. McCarthy, Langmuir, 2006, 22, 6234.

43 C. Birleanu, M. Pustan, V. Merie, R. Müller, R. Voicu, A. Baracu and S. Craciun, IOP Conf. Ser.: Mater. Sci. Eng., 2016, 147, 012021. 